\title{
Reflections on education - Machines or mentors: Mentors and mentorship. Education Excellence Lecture 2004
}

\author{
Ivan T Beck MD PhD FRCPC FACP MACG
}

\section{I:} $\mathrm{t}$ was a great honour to be asked to give the Education Excellence Lecture for 2004. Dr Desmond Leddin, our President, asked me to give a talk on the motivation for my work in this area, and what I would recommend to physicians contemplating a career in education. In preparing this talk, I had three issues to decide on: who was my audience; how was I to deal with today's pressure to use electronic equipment for learning; and, regarding my own motivation, how personal could I be about my own life experience.

Membership in the Canadian Association of Gastroenterology (CAG) has recently exceeded the 1000 member mark. At the time of my lecture, there were 634 active and 370 senior members. Of the acting members, 498 were gastroenterologists, 59 were basic scientists, 43 were in other medical specialties such as surgery, radiology and pathology and the remaining were GI nurses, research technicians, etc. Of the 370 senior members, most were gastroenterologists and clinical and basic scientists. Thus, the audience consisted mostly of gastroenterologists and basic scientists.

I have been the educator of gastroenterologists and surgeons. Some are in private practice, others are clinical teachers and many have become clinical investigators. I have also been the teacher of many basic scientists, and I could talk about how to stimulate science students to become investigators or residents to become devoted clinical gastroenterologists. Today, however, I will concentrate on how to stimulate residents to become clinical investigators and educators.

A clinical investigator is a physician who, in his or her clinical practice, critically observes patients. If the investigator notices the unusual - a symptom or relationship that does not fit into regular textbook medicine - he or she starts to consider that something new may have been discovered. Theories are built on new observations, and available scientific methods are used to prove or disprove a theory. If the results of the assumption prove to be correct, the finding is applied and new medical knowledge has been established. Involvement in research allows the investigator to meet internationally established clinical scientists and teachers at scientific meetings. This helps the researcher to gain knowledge in the newest developments in his or her field and, thus, become a better teacher and clinician. Most important, to be a good educator, the investigator should never be removed from practical medicine, closed up in a basic laboratory, but must instead remain a humanitarian clinician serving as an example and mentor for future generations (Table 1). There may be a variable balance emphasizing the model of a clinical teacher or that of a clinical investigator. These valued individuals need not be attached to a university because many community physicians do outstanding teaching in their own environments and participate in clinical research. Many of my previous residents who are in private practice are doing exactly that.

The second decision I had to make was whether I should discuss the effect of recent overwhelming pressure to use electronic machines for teaching. Many believe that computers and machines are the most important part of new developments in medical education. To some, today's ideal of a medical teacher may be either a PhD 'education expert' or a clinician who is adept in using educational technology. Machines, however, are not new. The first communication for education was a chisel on stone, where information was rather laboriously transmitted from one individual to many. The next development was stylus writing on papyrus and then the pen on paper. Early books were written and rewritten with outstanding penmanship. The big change occurred when Johann Gutenberg invented the press, producing a full reproduction of the Bible in 1456. The press was the first computer, which allowed rapid multiplication of knowledge. Electronic computers are nothing more than a newer method of extra rapid distribution of knowledge and, except for speed and ease of distribution, are no different from what one used to obtain from extremely rapid distribution of books and journals. Compact disc lectures facilitate the teaching of facts and are irreplaceable in the transmission of knowledge. However, they are inept at providing the philosophy and approach that mentors, in the tradition of Socrates, can provide. Computers today can interact with students, but the personal approach provided by body language cannot be replaced. In short, no one has learned from the chisel, internet or a $\mathrm{PhD}$ educator how to become a clinical teacher or investigator; only clinical mentors can provide that (Table 2).

Having decided not to spend more time on the influence of machines, I can now discuss how I became a clinical investigator and teacher, and how I would influence others to take up a similar career. I chose academic medicine because of the influence of my mentors, and I continue this path postretirement as a duty to my mentors, teaching and interacting with young people who may be influenced to undertake a similar career.

\footnotetext{
The Ivan T Beck MD Gastrointestinal Diseases Research Unit, Division of Gastroenterology, Departments of Medicine and Physiology,

Queen's University, Kingston, Ontario

Correspondence and reprints: Dr Ivan T Beck, Hotel Dieu Hospital, 160 Brock Street, Kingston, Ontario K7L 5G2.

Telephone 613-544-3310 ext 3058 or 613-544-0225, fax 613-544-3114, e-mail becki@hdh.kari.net

Received for publication June 28, 2004. Accepted September 23, 2004
} 


\section{TABLE 1}

Attributes of a clinical teacher and investigator

Critically observes patients

Notices the unusual

Builds theories on new observations

Uses available scientific methods to prove or disprove theories

Applies results to improve medical knowledge

Enjoys teaching clinical and basic sciences

Warmhearted, humane clinician

Although it may be very personal, I could not discuss what I have done as a teacher-investigator without reviewing what I learned from my mentors.

I started medicine as an undergraduate in Hungary. After World War II, my father held a diplomatic position in Switzerland as Commercial Attaché of Hungary. In 1948, when the Communist Party in Hungary took over political power, my father resigned and the family came to Canada in 1949. I spent 1945 to 1949 in Switzerland where I continued medical school. In my free time, I became involved in research. My first teacher was Prof Fritz Verzar in Basel, Switzerland (Figure 1A). A well-respected physiologist, he was the first to describe phosphorylation in sugar metabolism. His other interest was high altitude physiology. When I joined his laboratory as a medical student, he suggested that I participate in an ongoing study to investigate the relation of red blood cell count (RBC) and its osmotic resistance (OR) during ascent and descent from high altitude. The experimental subjects, Dr Andrew Sass-Kortsak (postgraduate fellow), two technicians and myself, proceeded to a research laboratory at Jungfraujoch at $3457 \mathrm{~m}$ above sea level, where we stayed for 11 days. While RBC and OR of the investigators and technicians were measured at Jungfraujoch every day, we also had a great time skiing on the glacier. On descent to Basel, RBC and OR were assessed for two weeks. We found that, on descent, RBC fell more rapidly than OR, probably because older cells were first destroyed. This, at that time, was a new observation and explained the mild unconjugated hyperbilirubinemia on descent. This was the research environment where a young medical student became enthusiastic about the joy of research. However, Prof Verzar was also an accurate and demanding investigator. If he found that we used slightly inaccurate methods, he made us redo the whole experiment, and I found that research was not always fun. My stay in his laboratory resulted in my first publication, in which Prof Verzar allowed me, the medical student, to be the first author. In his institute, I met many outstanding investigators, including Dr Sass-Kortsak, who later worked at the Toronto Hospital for Sick Children. Based on his contributions to Canadian pediatric hepatology, he was honoured with a named lecture at the Annual Meeting of the Canadian Association of Liver Disease ('The Andrew Sass-Kortsak Award Lecture'). What I learned from Dr Verzar, my first mentor, was far more than research; he gave me the opportunity to become friends with great investigators and taught me the necessity of accuracy and of allowing junior colleagues to be first authors in a publication (1).

At that time in European medical schools, to obtain wider experience, one could move from one university to another. After Basel, I spent two years at the University of Geneva where I graduated. Here again, in my free time I became involved in research and worked with Prof Edouard Frommel
TABLE 2

Characteristics of machines versus mentors

\begin{tabular}{l} 
Machines: Irreplaceable to transmit knowledge \\
Chisel - on stone \\
Stylus - on papyrus \\
Pen - on paper \\
Book - Gutenberg in 1456 created the first computer to distribute \\
knowledge rapidly \\
Computers - a newer method of rapid distribution of written and oral material \\
Courses and CD lectures - absence of direct integration with teacher \\
Mentors: Irreplaceable to provide philosophy and approach \\
Constant human interaction - provides attitude not just knowledge \\
\hline$C D$ Compact disc
\end{tabular}

(Figure 1B), who chaired the Department of Therapeutics (pharmacology). Working there held great importance for my whole life because this is where I met my wife Marjorie Favre, who was 'Chef de travaux' (Associate Director of Research) in the Department. In contrast to Prof Verzar, Prof Frommel was perhaps less accurate; he had the elan of a French man, was less demanding but had greater courage to change approach and go after new ideas. My publications in his laboratory reflect his multitudes of interest in several different areas. Again, he allowed his students to be first author in some of the papers $(2,3)$. In 1949 in Switzerland, I graduated with a Diploma in Medicine. To obtain a Doctorate in Medicine, I wrote an MD thesis in Prof Frommel's laboratory (4), and then I left for Canada.

Dr Frommel also taught me to look after my students, even after they completed their stay in my laboratory. He knew Dr Boris Babkin, the respected gastrointestinal (GI) physiologist in the Department of Physiology at McGill University, Montreal, Quebec, and wrote to him a warm letter introducing me. This introduction led to my appointment as Lecturer in Pharmacology at McGill, where I worked for three years. However, I missed clinical medicine and undertook an internship and residency at McGill. This is when I met Dr JSL Browne (Figure 1C) who later became my $\mathrm{PhD}$ supervisor. He was Head of the Department of Medicine at McGill. In the 1950s, he became blind. He resigned as the Head of Medicine and was appointed Head of the Department of Experimental Medicine. He was the founder of The Canadian Society for Clinical Investigation. Dr Browne was a sensitive humanist. He spent his early life in the Gaspé Peninsula of Quebec where there is ongoing friendly interaction between the 'two solitudes' of French-and English-speaking Canadians. This experience was perhaps the reason why he could bring together scientists of very different backgrounds. He was the first to combine the work of McGill and of the University of Montreal, Montreal, Quebec, and it is in his department that I met, among others, Dr Jacques Genest. Dr Browne's most important attitude was his care for his students. I recall that when I finished the last page of my $\mathrm{PhD}$ thesis, I developed tracheobronchitis and was in hospital. My wife typed out the last part of my thesis (5) and took it to Dr Browne. Although he was practically blind, he took the voluminous multiple copies of the thesis to the university and passed it through all the administrative hurdles necessary for the submission of a $\mathrm{PhD}$. What he taught me was how to bring together people of different backgrounds in research and to have an ongoing care for students. 

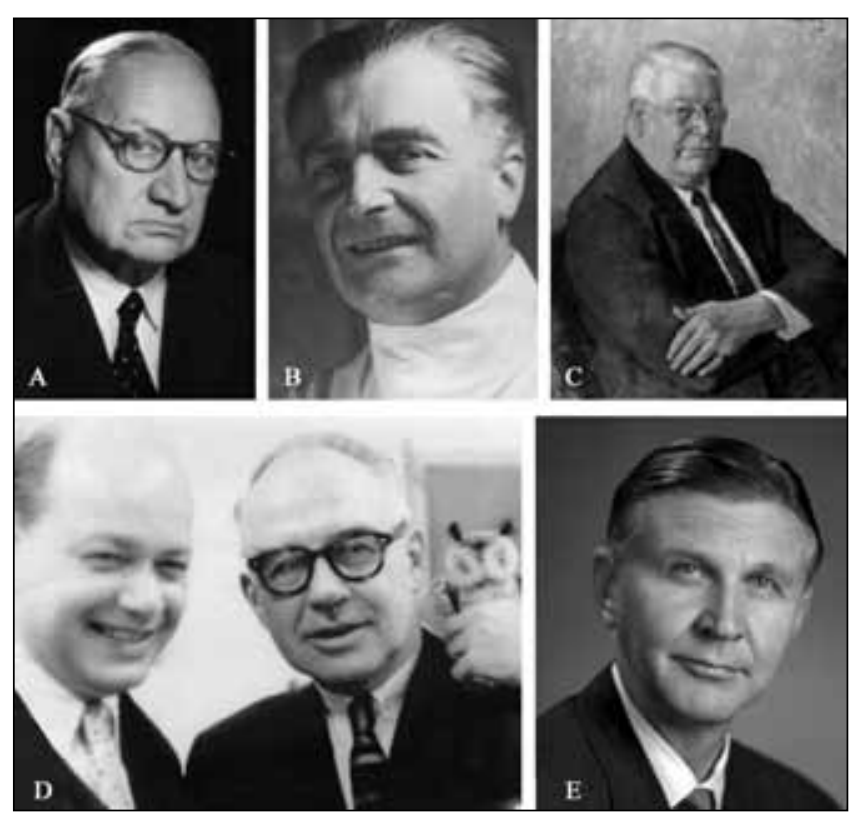

Figure 1) The author's mentors: A Professor Fritz Verzar, photograph courtesy Dr Ivan Beck; B Professor Edouard Frommel, photograph courtesy Dr Ivan Beck; C Dr JSL Browne, portrait obtained from Osler Library, McGill University, reproduced with permission; D Dr Richard McKenna and the author at a party at the author's home; because of his glasses and debts of knowledge, Dr McKenna was often referred to as the 'owl', photograph courtesy Dr Ivan Beck; E Dr Charles Code, picture obtained from Mayo Clinic, Rochester, Minnesota USA, reproduced with permission

My main mentor in gastroenterology was Dr Richard McKenna (Figure 1D). He needs no introduction to the CAG. Details of his life and contributions to gastroenterology and science were reviewed previously $(6,7)$. During our association, he became one of my closest friends. Dr McKenna was a superb clinician who taught me to closely cooperate with surgeons and to maintain a multidisciplinary approach to patient care, research and education. What I learned from Dr McKenna was how important it is to be a warm-hearted clinician who is capable of carrying out research while still looking after his or her patients, and how to help young physicians in their first steps to becoming academic physicians.

There is one other person whom I consider to be a mentor, although we never worked closely together. Dr Charles Code (Figure 1E) of the Mayo Clinic, Rochester, Minnesota, USA, was external reviewer of my PhD thesis. Dr Code is considered the father of esophageal motility (8). Although my thesis was on acute pancreatitis, based on his wide knowledge, he reviewed it critically and made major contributions to the manuscript. We became friends when we co-organized the joint American Gastroenterological Association (AGA) and CAG meeting in Montreal in 1966. At that time, he was President of the AGA and I was Secretary of the CAG. My contact with Dr Code influenced three major roles in my research and teaching. First, he demonstrated that although one can be expert in one subject (in his case, motility), one has to remain well-versed in almost all areas of gastroenterology. Second, he stimulated me to become involved in GI motility and encouraged me to establish the first Canadian motility laboratory at McGill. Third, he taught me that with friendly

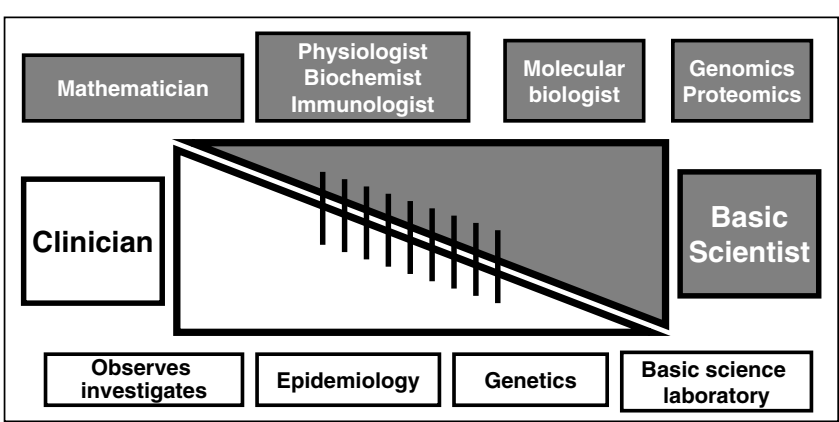

Figure 2) Interaction of clinical investigator and basic scientist. White triangle indicates clinician; grey triangle indicates basic scientist; grey and white rectangles indicate involvement mainly but not exclusively by basic scientist or clinician; vertical lines indicate areas of interaction

ongoing questioning in many different areas of gastroenterology, one can stimulate investigators to further improve their work. Those who attended the AGA meetings during the 1960s, 1970s and 1980s will remember Dr Code with his slight limp (he had polio as a child) going to the microphone after almost every paper and asking questions that usually provided new ideas or improvements to the further work of the investigator. It is his mentorship that stimulated me to attempt to maintain an overall knowledge of gastroenterology and to realize the importance of an educator actively participating at meetings.

In summary, I have learned that, to become an investigator and educator, I needed input from several mentors. Each had a different influence on my approach to research and education. Prof Verzar, the physiologist, taught me that research could be fun and about the importance of being accurate and critical of methodology. Prof Frommel, the pharmacologist, demonstrated that one can dream and do many different things and still succeed. Both taught me the importance of basic science in my future research and about the need to involve undergraduate students as a way of stimulating their research interests. From Dr Browne, I learned about humanity and about combining different groups of investigators. Dr McKenna taught me how to be a warm clinical gastroenterologist who uses a multidisciplinary and considerate approach to patients and to research. Dr McKenna also taught me the pleasure of becoming an academic physician. From Dr Code, I learned the importance of educators actively participating in meetings. From all, I learned to care for my trainees. Having had this background, it was not difficult to establish my own goals to become a clinical investigator and teacher.

Based on my experience in basic science laboratories, I developed my concept of the relationship between clinical investigators and basic scientists (Figure 2). The left side of the white triangle demonstrates the pure clinician. An observant clinician may notice that a patient may exhibit unusual events that do not fit into textbook medicine: new symptoms or unusual frequency of family occurrence. To ascertain that this is so, an epidemiological approach using appropriate mathematics is needed to study the frequency of this relation. If this turns out to be unusual, a genetic approach may be the next step. Another clinical scientist may become fascinated by the abnormal pathophysiology of a certain aspect of the disease, and a basic science laboratory using animal, cellular or subcellular models proceeding towards the genomic or proteomic 
TABLE 3

\section{Organization that facilitates teaching and research}

Integrated care by
Physician
Basic scientist
Resident
Undergraduate student
Postgraduate student
Nursing staff
Research nurse
Integrated physical unit
Physician's offices
Residents and research trainee's offices
Basic scientist's offices
Conference room
Inpatient and outpatient nursing unit
Endoscopy suite
Function and motility laboratory
Research laboratory

would be the appropriate approach. On the right side of the grey triangle is the pure basic scientist who is entirely remote from clinical medicine, doing genomics or proteomics. At one point, this work becomes the basis of the work of the molecular biologist and then the physiologist, or the physiologist may use genomics and proteomics to obtain answers to a problem of molecular biology. Inflammatory bowel disease is a good example. Clinicians first observed familial occurrence. Epidemiologists had to prove that this observation was correct. With the development of genomics on the right side of the darker triangle, it is now possible to investigate the genetics of inflammatory bowel disease. The other aspect was the observation by other investigators of the disturbed pathophysiology of chronic inflammation. To understand this, clinicians, in cooperation with basic scientists, developed models to study the inflammatory events; finally, clinicians applied these findings to human disease and therapy. The therapeutic use of tumour necrosis factor-alpha antibodies has developed through this route. The relative contribution of clinicians and basic scientists is demonstrated by the white and grey triangles. In the white triangle, from left to right, fewer clinicians become involved in the depths of scientific approach while, from right to left (grey triangle), fewer basic scientists are involved in observation of clinical outcome. The two sides intertwine in the middle two-thirds, where the vertical black lines indicate where clinicians and basic scientists can most usefully interact in combining their knowledge. This is the concept that I used to involve and stimulate basic scientists to become interested in clinical outcome, and to stimulate residents to become researchers and, through research, better clinical educators.

Because I needed several mentors to become a clinical scientist and educator, I hoped to establish a unit where residents could find several possible mentors in the early part of their training. To achieve this, there is a need to establish a unit where physicians, basic scientists, residents, undergraduate and postgraduate students, nursing staff and research technicians interact closely through ongoing communication (Table 3). It is in this type of unit that one can stimulate a resident who makes an unusual observation in the endoscopy suite to initiate

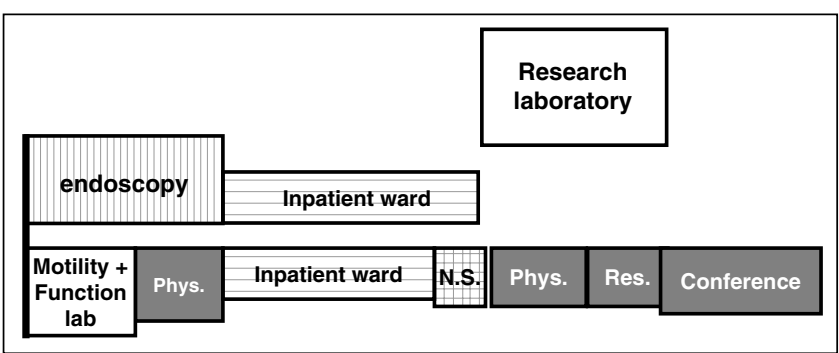

Figure 3) Physical layout of the first integrated unit for patient care and research. Grey indicates physician offices (Phys), residents' office (Res), conference room; white indicates motility and clinical gastrointestinal function laboratory and nearby research laboratory; vertical stripes indicate endoscopy and $x$-ray unit; horizontal stripes indicate inpatient wards (18 beds); chequered pattern indicates nursing station (NS)

a clinical study, possibly through involvement in the motility or the basic research laboratory. It is also possible to stimulate basic researchers and science students to come to medical rounds and initiate a clinical investigation by obtaining biopsy specimens to complete their basic science study. This integrated approach to patient care and research was possible when I was invited to Queen's University, Kingston, Ontario, and could design a unit, which at that time was unique in integrating patient care, research and teaching in a single setting (Figure 3). The unit was established at Hotel Dieu Hospital, Kingston, Ontario, where, on the same floor, there was an endoscopy unit, a motility and function laboratory, an 18-bed in-patient ward, a nursing station, offices for gastroenterologists and residents, a conference room and a nearby research laboratory. I was allowed to bring my nurse associate, Mrs Elizabeth Phelps, from Montreal to Kingston. She stayed for two years to help to set up the unit. She recruited Eleanor Whalen (Head Nurse) and Sharon McGregor (Assistant Head Nurse) and transmitted the principle that physician-nurse cooperation is the best way to provide patient care, research and teaching. The first physician to join the unit was Dr Francis Milligan. However, after one year, he left to join the gastroenterology group at Johns Hopkins University, Baltimore, Maryland. Dr Laurington Da Costa joined in 1970. We quickly developed a close friendship and a fully integrated joint practice, which allowed for looking after patients and residents in cooperation. The inpatient nursing station was adjacent to the physicians' offices, allowing for ongoing contact with the head nurse for integrated direction. Dr Da Costa, myself, Eleanor Whalen (Head Nurse), Mary Smith (Assistant Head Nurse and Research Protocol Nurse), Sharon McGregor (Endoscopy Nurse) and the technicians in the motility and function laboratory could integrate patient movement from in-patients to the endoscopy or motility unit.

I was allowed to move my Medical Research Council (MRC) operating grants to Kingston. Furthermore, I successfully obtained a Clinical Investigation Unit grant in gastroenterology. This allowed for the salary of a $\mathrm{PhD}$, two technicians and, most important, admission of in-patients for scientific investigation of unusual problems. As a result, in a closely adjacent basic science laboratory, Dr Da Costa, Peter Dinda, $\mathrm{PhD}$ (who joined the unit as an MRC-supported biochemist one year after I arrived), and I carried out research with graduate students and residents. There was constant exchange from the ward to the research laboratory. Educational clinical rounds considered that every patient might represent a 
research problem. With this in mind, we were able to stimulate our residents to observe the unusual and to try to resolve problems that came up on rounds. We tried to define a problem that could be resolved during the two-year residency. Our residents set out a number of outstanding clinical investigative studies. I will mention only a few because they may be of specific historical interest. For instance, this year's CAG President, Dr Leddin, decided when he was a GI resident at Queen's to evaluate the usefulness of the recently published isotope technique for the assessment of the extent and severity of Crohn's disease. This was done in conjunction with fellow resident Dr John McKaigney and supervised by Dr William Paterson (this year's CAG President-Elect), who had recently returned to Queen's. It was found that the test lacked sensitivity with respect to disease extent, but was useful to assess severity (9). Another example is the study organized by Dr Stephen Vanner, at a time when he was a resident, with a surgical resident who rotated through our service, Dr Hugh MacDonald. At rounds, we discussed the difficulties encountered by patients during colonoscopy preparation with large amounts of electrolyte solution. We considered that possibly a more rapid and less tiring preparation could be obtained using an oral Fleet enema (Johnson \& Johnson/Merck, Canada) as a phosphosoda laxative. Once published, this study became the basis of the phosphosoda preparation for colonoscopy (10). Clinical residents sometimes became involved in the research laboratory. For instance, we had an unusual event when a patient arriving from South Africa was admitted with cholera (11). Our resident, Dr Raymond Bourdages, worked with the research laboratory on biopsies obtained from the patient (12).

At Queen's, there was a strong gastroenterology unit at Kingston General Hospital, Kingston, Ontario with Drs William Depew, Aubrey Groll, Jerome Simon and Leslie Valberg doing outstanding work. Residents rotated in both units; later, for better integration, the two units were combined first for education and research, and later in location (13-16).

The multidisciplinary approach was further facilitated when the Crohn's and Colitis Foundation of Canada called for a competition for the establishment of an intestinal diseases research unit. At that time, there was already close cooperation between the research members of the GI Unit and many different basic scientists, consisting of Dr Gerry Morris (Department of Biology), Dr Myron Szewczuk (Immunology), several surgeons, pathologists and epidemiologists. This allowed for a joint submission to be prepared for the grant. The Queen's submission was among five finalists, but because only two grants were provided, the University of Calgary, Calgary, Alberta, and McMaster University, Hamilton, Ontario, received the units. However, the work of preparing a joint submission resulted in close cooperation between a number of multidisciplinary investigators. With the support of Hotel Dieu Hospital, laboratory space was provided not only for members of the GI Unit but also for all basic scientists who wished to establish their laboratory at Hotel Dieu Hospital. This concentration of investigators and laboratories adjacent to the clinical unit allowed for the establishment of the Gastrointestinal Disease Research Unit in 1983. Close cooperation with the Department of Physiology was facilitated by establishing joint courses.

In clinical teaching, it is important to sense which resident is not interested in either teaching or research. There is a tendency by educators, including The Royal College of Physicians and Surgeons of Canada program reviewers, to officially require residents to do research during their training. I believe it is wrong to force trainees to do research against their will because this could discourage them to continue ongoing postgraduate education and to attend meetings run by 'academic physicians'. We need to educate good clinical gastroenterologists, who need not necessarily benefit from research.

With the ongoing expansion of clinical and research gastroenterology in 1989, the unit moved to an entire floor of the hospital. In the new location, the original unit's principle of maintaining functional integration in a physically coordinated space was maintained. Research laboratories, surgical and medical offices, offices for residents, the function and motility laboratory, the endoscopy and endoscopy recovery units, the conference room, the out-patient nursing station and the inpatient nursing unit were all on the same floor. A multidisciplinary laboratory was four levels below with a direct elevator from the endoscopy unit to the research laboratory. As before, a prominent role was given to the basic scientists. Our residents were continuously stimulated to interact with the basic science laboratory and the motility and function laboratory. In April 1989, the unit was officially opened by the the Premier of Ontario, the Honourable David Peterson, and I was honoured to have the clinical and the research unit named 'The Ivan T Beck MD Gastroenterology Unit and The Ivan T Beck MD Gastrointestinal Disease Research Unit' (13-15).

The most important issue that I learned from my mentors was to care for my trainees. I also learned that, to become an experienced teacher and investigator, there is a need for input from several teachers. At Queen's, during the early stages, Drs Da Costa, Groll, Simon and Valberg acted as mentors. Furthermore, my colleagues and I helped our residents to obtain further training. Once their full training was completed, we attempted to find a post-training position for individuals interested in research or teaching in locations where their time for these endeavours was protected. If requested, we helped with writing their first research application. As their early educators, we were available for advice, maintained contact and were ready to help. In a recent article (17), Dr Depew and I reviewed the Canadian Research Fellowship program between 1986 and 1997. One of the questions asked of the fellows graduating during these years was how satisfied they were with their overall supervision, technical skill training and manuscript preparation. Most residents were highly satisfied with most of these issues, but many noted that their mentor did not help them in preparing their first grant application (Figure 4).

I believe this was not the case in our unit. At Queen's, my previous fellows, Drs Depew, Paterson and Vanner, obtained major peer-reviewed grants on first application and, with their co-workers, are doing better than I ever did. After my retirement, between 1992 and 2002, Dr Paterson and several of my previous fellows, Drs Depew and Vanner, obtained many key research and educational grants. These included the CAG Motility Education Centre (1995 to 2000), the Centre for Innovation and Research in Gastrointestinal Sciences award (2000) and the Multidisciplinary Canadian Institutes of Health Research (CIHR) Research Training Program Grant (2002 to 2008). In addition, they affiliated many new basic scientists: Dr Ceredwyn Hill from Calgary, Dr Michael Blennerhassett from McMaster, Dr John McLeod as a CIHR research professor, and several clinical scientists such as Dr Mark Ropeleski with an interest in mucosal inflammation and signal transmission, and Dr Chris Justinich in pediatric 


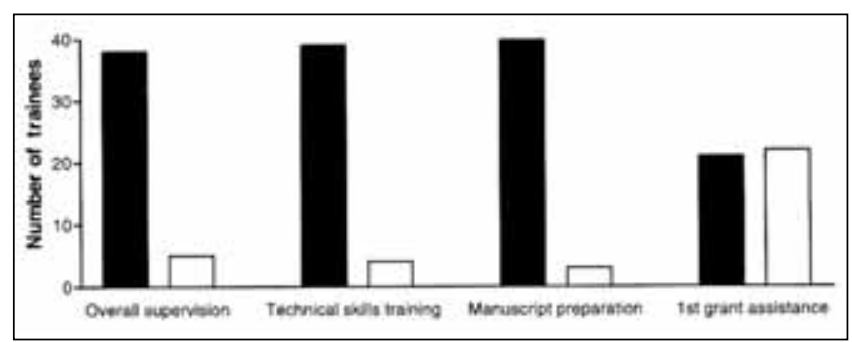

Figure 4) Supervision of research fellows graduating from 1986 to 1997 by their mentors. Data based on the response of 45 fellows indicate that $85 \%$ of fellows were satisfied with overall supervision, technical skill training and manuscript preparation. However, 55\% were somewhat dissatisfied with their mentor's help in preparing their first post-training research application. Black bar indicates fully satisfied; white bar indicates somewhat dissatisfied. Reprinted with permission from reference 17

gastroenterology. Two new clinical investigators, Dr Jacob Louw from South Africa and Catharine Low, one of our previous residents, have recently joined. In the tradition of the unit, arrangements have been made for two of the fellows, Drs Michael Beyak and Lawrence Hookey, to obtain further training abroad and they will subsequently return to the unit. With Dr Paterson taking over the direction of the Division of Gastroenterology in 2003, Dr Vanner carries on the tradition of the Research Unit.

In retrospect, I must admit, I was extremely lucky to have taught at a time when academic teaching was fully supported. Provincial and federal governments, based on the Royal Commission on Health Services report by EM Hall in 1965 (18), believed in the importance of clinical investigation of complex medical problems and supported clinical investigation. The MRC 'Clinical Investigation Unit' allowed for research and teaching on interesting patients. The situation started to change in the 1980s and culminated around 1990, when, at a conference of all Deputy Ministers of Health, and based on reports by two nonmedical economists Barer and Stoddart (19-31), most provincial governments accepted the principle that specialist and hospital treatments are too expensive. This resulted in decreased training of physicians, a shift from specialists to family physicians and sudden bed shortages (32). Today, only extremely sick patients are admitted to hospital. The first thought about these patients is not what one can learn from them, and thus how can we better their medical care, but 'when can we discharge them?' Unfortunately, Barer and Stoddart (33) restated the concept of shifting from specialists to family medicine and decreasing hospital beds in 1999, even at a time when the outcome of these restrictions was already felt. Unfortunately, this view has been accepted and promoted in the recent Romanow Commission report (34) and, thus, this situation will continue. Another change that makes research and teaching more difficult today is the government-commanded reorganization of hospitals, without consideration of the functional workings of its sections. The physical coordination of the gastroenterology unit was altered when the in-patient ward was moved to Kingston General Hospital, and recent plans are to further separate research laboratories from the clinical function and motility laboratory.
I am not certain whether I could have achieved what I have done under today's conditions. I admire my colleagues who, under these circumstances, still have the stamina to be examples of outstanding clinicians, researchers and educators, and to remain as mentors for the next generation.

Dr Leddin asked me to comment specifically on the key issues of success and my recommendations for becoming a successful mentor in the future. There are many that I could mention but there are some important ones, related to different levels of training of students, residents and new staff, that I would like to highlight. Mentorship based on personnel contact can first be established at the undergraduate level during the clinical clerkship. Success may depend on the duration of clerkship in a single unit. A longer duration with a possible mentor in a unit where teaching, research and clinical practice are interwoven may provide opportunities to influence budding clinicians to undertake a similar career. In the past, clinical clerkship lasted eight to 10 weeks on the same unit. Personal interaction could be easily achieved between teachers and clinical clerks. With reorganization of the curriculum, where it is believed that everyone has to be exposed to everything, clerkships have been cut to two to four weeks. This short duration, coupled with new time rules to be off after night duties, means that clerks are more often off than in the ward. They cannot be mentored because most of the time there is not enough contact to even remember their names. To correct this, steps may have to be taken to curriculum committees to provide longer duration of contact in the medical specialties at this early stage of clinical training.

The most pleasurable direct personnel interaction and teaching among staff, clerks and residents often occurs at the end of an exciting night experience. I remember how often, after an endoscopy, we sat down over a cup of coffee to discuss the case and possibly many other issues, often unrelated to the present case. Lasting friendships could develop under conditions where there is no ongoing pressure felt during the regular work of the day. Although this may not be acceptable to student and resident organizations, I believe an increase in the number of night duties in a unit where staff participates in night call may provide further opportunities for mentorship.

It is most important to highlight unresolved problems to medical and GI residents during clinical rounds. To resolve these, residents may be encouraged to carry out a careful review of the literature, thus becoming a better teacher, or to initiate a research study, both of which can possibly lead to enthusiasm towards academic medicine. I have discussed the importance of the 'problem-oriented round' before. However, I believe this aspect of mentorship is so important that it merits reiteration in this section on suggestions. The 'problem-oriented round' is even more important today, where forward thinking tends to be inhibited on rounds where patient care tends to be based on 'evidence-based medicine'.

Encouragement and support may be needed when investigators take up their first position after several years of further training. There are several reasons why, unless carefully protected, the returning new staff may be deterred from their primary goal of clinical teacher and investigator, and become primarily involved in clinical work. Years after being away, they are itching to prove themselves as able clinicians and attempting to become fully involved in all aspects of the department with committees and other nonessential undertakings. Second, setting up a laboratory is difficult. They must 


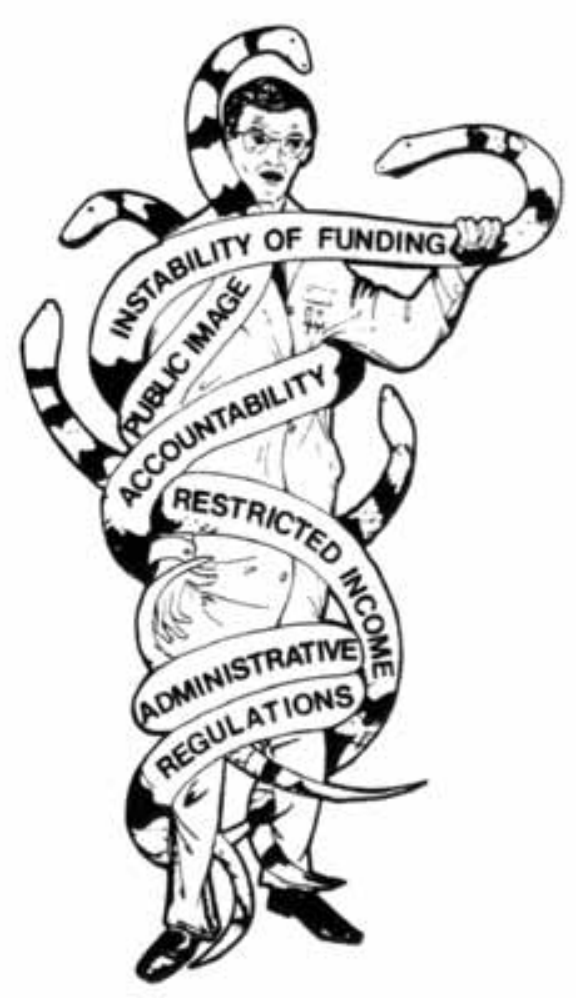

Figure 5) Factors that 'strangled' the clinical investigators in 1981. Reprinted with permission from reference 6

wait for new equipment, funding and technical help to set up their experiments. Finally, there may be a financial advantage in doing more clinical work. The director, who now has to act as a mentor, must be prepared to overcome these. The clinical investigator needs to have clear-cut time to do experiments; however, a well-defined time for clinical work is absolutely necessary to maintain the ideals of a clinical teacher. Departments tend to involve new staff in committee work and they enthusiastically become involved. New staff need to be protected from this pressure; most important, it has to be ascertained that by doing research, the educator and/or investigator has the same clinical income as other members of the department of his or her rank. Mentorship should not be finished after completion of training and should be available as long as both parties enjoy it.

In 1981, I was honoured to present the RD McKenna Lecture. The title was 'Canadian gastroenterology: Yesterday, today and tomorrow' (6). At that time, I expressed considerable worry about the diminishing number of clinical scientists and suggested that if this were allowed to continue it may eventually destroy the scientific contributions of Canadian gastroenterology (Figure 5). Already in 1981, several factors resulted in a decreased desire of residents to become clinical scientists. There was instability of funding, a situation which has not changed. Excessive accountability and numerous administrative regulations already have been factors. Reasonable accountability is necessary and is to be expected. However, I believe that this should be well-directed and not simply a reproduction of official documents in innumerable copies that are sent to multiple places for approval.

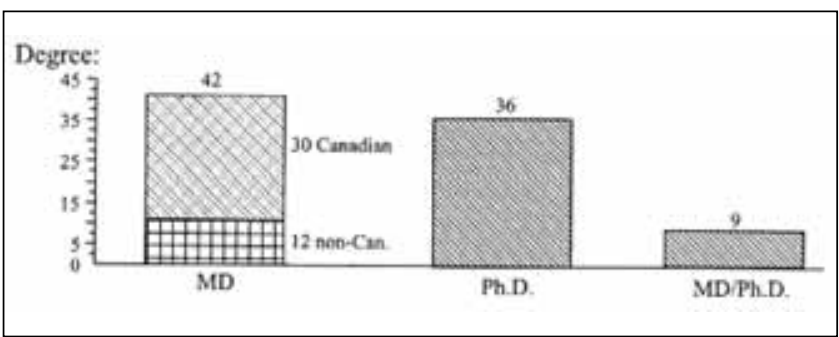

Figure 6) Distribution of MDs and PhDs in the Canadian Association of Gastroenterology Fellowship program, 1992 to 2002. The majority of trainees were MDs or MD/PhDs, suggesting a bright future for clinical scientists. Reproduced with permission from reference 36

Restricted personal income of academic teachers compared with practicing gastroenterologists was already a problem. There was a perception of diminished public image. At that time, there was government-induced pressure to produce more family physicians, and many students and residents seemed to have accepted the attitude that the public relates to actual physicians much better than to someone who is mainly in a laboratory. I made it clear in 1981, and I re-emphasize it today, that in order to be a good clinical scientist and teacher, one has to be an outstanding clinician. If so, the public image of the clinical investigator should increase rather than suffer.

I am pleased to see that, in spite of these difficulties, Canadian research fellowship programs have done extremely well. Seventy-one per cent of those in training between 1986 and 1997 currently have academic positions (35). Of research fellows between 1992 and 2002, the majority are MDs or $\mathrm{MD} / \mathrm{PhDs}$ (Figure 6) (36). The fellows trained in these eight years published 175 peer-reviewed research papers and 43 reviews, and several have written book chapters (37). Thus, with these new trainees, Canadian gastroenterology has done extremely well in most areas of research. In spite of what appeared worrisome in 1981, Canadian ingenuity and education overcame these difficulties, and Canadian research and clinical teaching have flourished (38).

In conclusion, I believe my mentors have made me what I am. Hopefully some of my younger, and by now not-so-young, students, residents and research fellows may remember me as their mentor. If so, I achieved my main purpose in medicine. To continue my advice to investigators is to question all established 'facts'. Teachers should continue to transmit the thought of ongoing changes of knowledge and to learn to adapt to those changes. One should remember what Claude Bernard wrote in 1861 in his introduction to the study of experimental medicine: "It is that we do know which is a great hindrance to our learning which we do not know" $(39,40)$.

ACKNOWLEDGEMENTS: I received the honour of this award due to the support of my wife, Marjorie, and my daughter, Dr Cynthia Beck; my early coworkers Drs Larry Da Costa and Peter Dinda; the nursing staff, technicians and secretaries of the GI Unit; medical, surgical and basic science colleagues; all my medical, surgical and basic science trainees; those who became clinical investigators or teachers and specifically those who joined the Division at Queen's, with new basic scientists who carry out the tradition of the training of clinical investigators and educators much better than I ever did. I am indebted to Kim Flynn, a secretary who joined and then stayed with the GI Unit for 20 years, for putting up with my writing and rewriting of this manuscript and to Anne Rutherford for editorial help. 


\section{REFERENCES}

1. Beck I, Sass-Kortsak A, Verzar F. Resistezanderung der Erythrocyten by der Abnahme ihrer Zahl beim Abstieg aus grossen Hohen. Basel: Benno-Schwabe \& Co, 1947:75-82.

2. Frommel E, Beck IT, Vallette F, Favre M. L'action de l'ester diethylaminoethylique de l'acid phenylcyclopentane carboxylique (Parpanit) sur le systeme neveux vegetatif. Son action anesthetique et anticonvulsante. Arch Int Pharmacodyn 1949;78:379-94.

3. Beck IT, Favre M, Frommel E. Le role de la prostigmine sur l'activite de la cholinesterase musculair au cours de la fatgue. J Physiologie 1947;39:467-72.

4. Beck IT. L'action de l'Atebrine (Quinacrine) sur le system nerveux vegetative: Antagonisme entre l'atebrine d'une part et l'acetylcholine, l'adrenaline, l'histamine et la chlorure de Barium d'autre part. Geneva: Universite de Geneve Faculte de Medicine, 1944.

5. Beck IT. On the role of protelytic enzymes in the pathogenesis of acute pancreatitis. Montreal: McGill University, 1963.

6. Beck IT. Canadian gastroenterology: Yesterday, today and tomorrow. Clin Invest Med 1982;5:93-107.

7. Beck IT. History of the first 30 years of the Canadian Association of Gastroenterology. Can J Gastroenterol 1992;6:345-64.

8. Code CF, Creamer B, Schlegel JF, Olsen AM, Donoghue EF, Andersen HA. An atlas of esophageal motility in health and disease. Springfield: Charles C Thomas, 1958.

9. Leddin DJ, Paterson WG, DaCosta LR, et al. Indium-111-labeled autologous leukocyte imaging and fecal excretion. Comparison with conventional methods of assessment of inflammatory bowel disease. Dig Dis Sci 1987;32:377-87.

10. Vanner SJ, MacDonald PH, Paterson WG, Prentice RS, Da Costa LR, Beck IT. A randomized prospective trial comparing oral sodium phosphate with standard polyethylene glycol-based lavage solution (Golytely) in the preparation of patients for colonoscopy. Am J Gastroenterol 1990;85:422-7.

11. Bourdages R, Beck IT. A case of cholera in Kingston, Ont. CMAJ 1976;115:393-6.

12. Beck IT, Dinda PK, Bourdages R, Beck M. Normal sugar uptake in vitro by small-bowel biopsies from a patient with cholera. Am J Dig Dis $1977 ; 22: 38-9$.

13. Deslaurier JV. Hotel Dieu Hospital, 1845-1995. Kingston: Hotel Dieu Hospital, 1995.

14. Angus M. Kingston General Hospital, a social and institutional history. Montreal: McGill-Queens University Press, 1973.

15. Beck IT, Depew WT. The Ivan T Beck MD Gastrointestinal Diseases Research Unit. In: Jennings DB, ed. A Scrapbook of Memories 1954 to 2004. Kingston/Belleville: Essence Publishing/Epic Press, 2004:125-130.

16. Beck IT, Depew WT. Gastroenterology at Queen's University. In: Jennings DB, Ed. A Scrapbook of Memories 1954 to 2004. A Historical Tribute to the Sesquecential. Kingston/Belleville: Essence Publishing/Epic Press, 2004:157-164.

17. Beck IT, Depew WT. Canadian research fellowship training programs in digestive sciences: Achievements and challenges. Clin Invest Med 2001;24:44-53.

18. Hall EM. Royal Commission on Health Services 1964-65. Ottawa: Queen's Printer, 1965.

19. Barer ML, Stoddard GL. Toward integrated medical research policies for Canada. Federal/Provincial/Territorial Conference of Deputy Ministers of Health, 1991.

20. Barer ML, Stoddart GL. Toward integrated medical resource policies for Canada: 1. Background, process and perceived problems. CMAJ 1992;146:347-51.
21. Stoddart GL, Barer ML. Toward integrated medical resource policies for Canada: 2. Promoting change - general themes. CMAJ 1992;146:697-700.

22. Stoddart GL, Barer ML. Toward integrated medical resource policies for Canada: 3. Analytic framework for policy development. CMA] 1992;146:1169-74.

23. Barer ML, Stoddart GL. Toward integrated medical resource policies for Canada: 4. Graduates of foreign medical schools. CMAJ 1992;146:1549-54.

24. Stoddart GL, Barer ML. Toward integrated medical resource policies for Canada: 5. The roles and funding of academic medical centres. CMAJ 1992;146:1919-24.

25. Stoddart GL, Barer ML. Toward integrated medical resource policies for Canada: 6. Remuneration of physicians and global expenditure policy. CMAJ 1992;147:33-8.

26. Barer ML, Stoddart GL. Toward integrated medical resource policies for Canada: 7. Undergraduate medical training. CMAJ 1992;147:305-12.

27. Barer ML, Stoddart GL. Toward integrated medical resource policies for Canada: 8. Geographic distribution of physicians. CMAJ 1992;147:617-23.

28. Barer ML, Stoddart GL. Toward integrated medical resource policies for Canada: 9. Postgraduate training and specialty certification. CMAJ 1992;147:999-1005.

29. Stoddart GL, Barer ML. Toward integrated medical resource policies for Canada: 10. Information creation and dissemination. CMAJ 1992;147:1325-9.

30. Stoddart GL, Barer ML. Toward integrated medical resource policies for Canada: 11. Improving effectiveness and efficiency. CMAJ 1992;147:1653-60.

31. Barer ML, Stoddart GL. Toward integrated medical resource policies for Canada: 12. Looking back, looking forward. CMAJ 1993;148:29-32.

32. Beck IT. Decrease of funds for "Sickness Care" in the "Health Care" budget. Ann R Coll Physicians Surg Can 2002;35:3. (Abst)

33. Stoddart GL, Barer ML. Will increasing medical school enrolment solve Canada's physician supply problems? CMAJ 1999;161:983-4.

34. Romanow RJ. Building on values. The future of health care in Canada. Ottawa: Government of Canada, 2002.

35. Beck IT, Depew WT. Canadian research fellowship training programs in digestive sciences: Achievements and challenges. Clin Invest Med 2001;24:44-53.

36. McKay DM, Daniels S. Canadian Association of Gastroenterology Canadian Institutes of Health Research - pharmaceutical partner postdoctoral operating fellowship programme: An outstanding success that continues to excel! Can J Gastroenterol 2003;17:437-9

37. McKay D, Canadian Association of Gastroenterology Research Committee. The Canadian Association of Gastroenterology Research Committee report: Continued commitment to promoting excellence in gastrointestinal related research. Can J Gastroenterol 2003; $17: 385-7$.

38. Beck IT. Disproportion of economic impact, research achievements and research support in digestive diseases in Canada. Clin Invest Med 2001;24:12-36.

39. Bernard C. Introduction à l'étude de la médecine expérimentale. Paris: J-B Baillière, 1865.

40. Bernard C, English translation by Henry Copley Greene. An Introduction to the Study of Experimental Medicine. New York: Macmillan, 1927. 


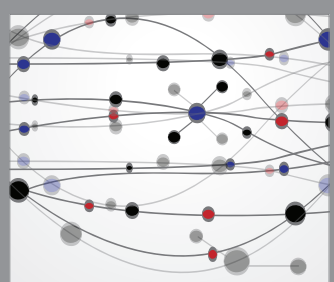

The Scientific World Journal
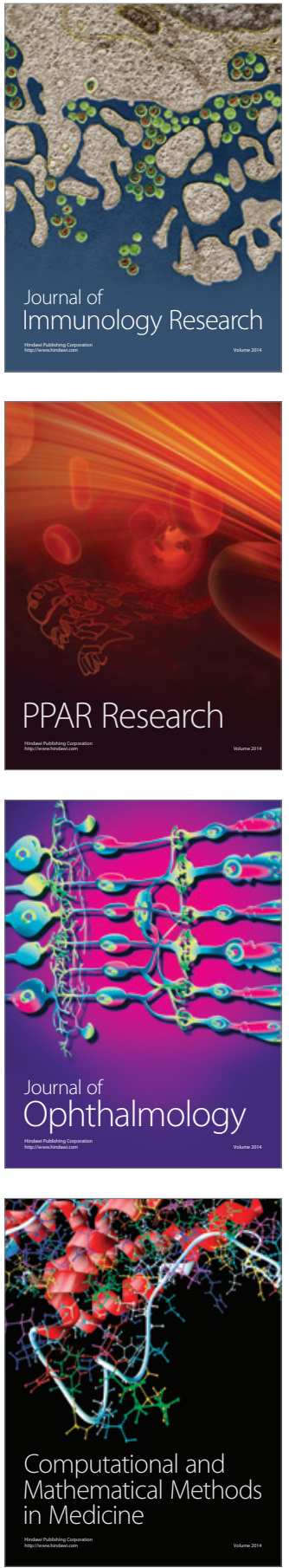

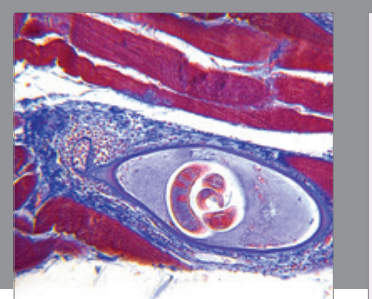

Gastroenterology Research and Practice

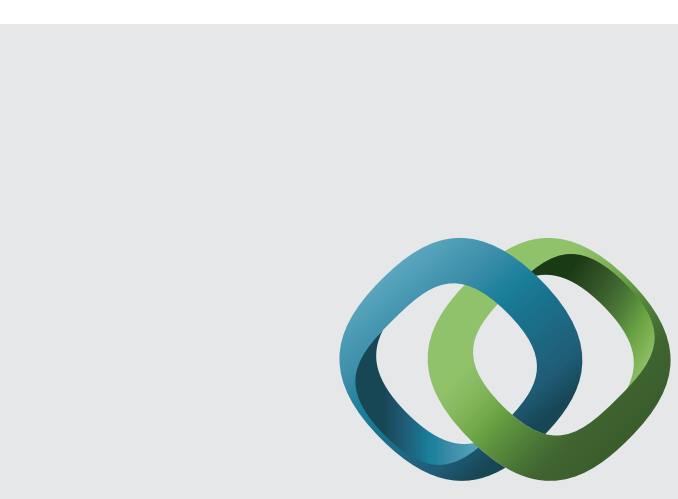

\section{Hindawi}

Submit your manuscripts at

http://www.hindawi.com
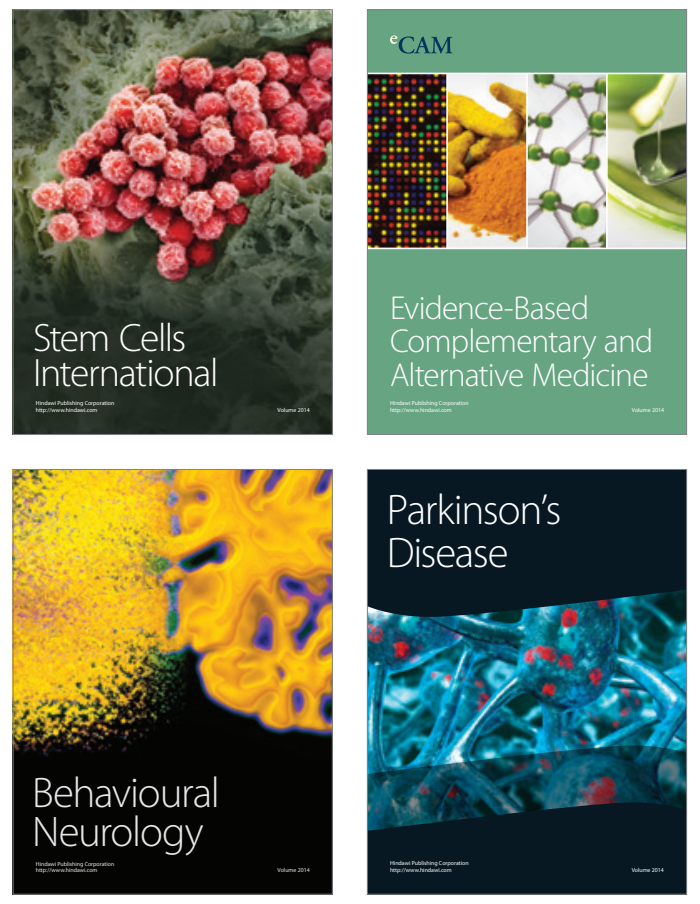
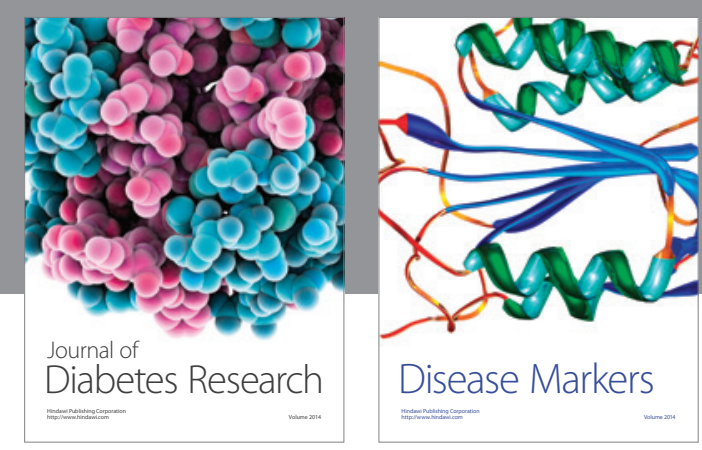

Disease Markers
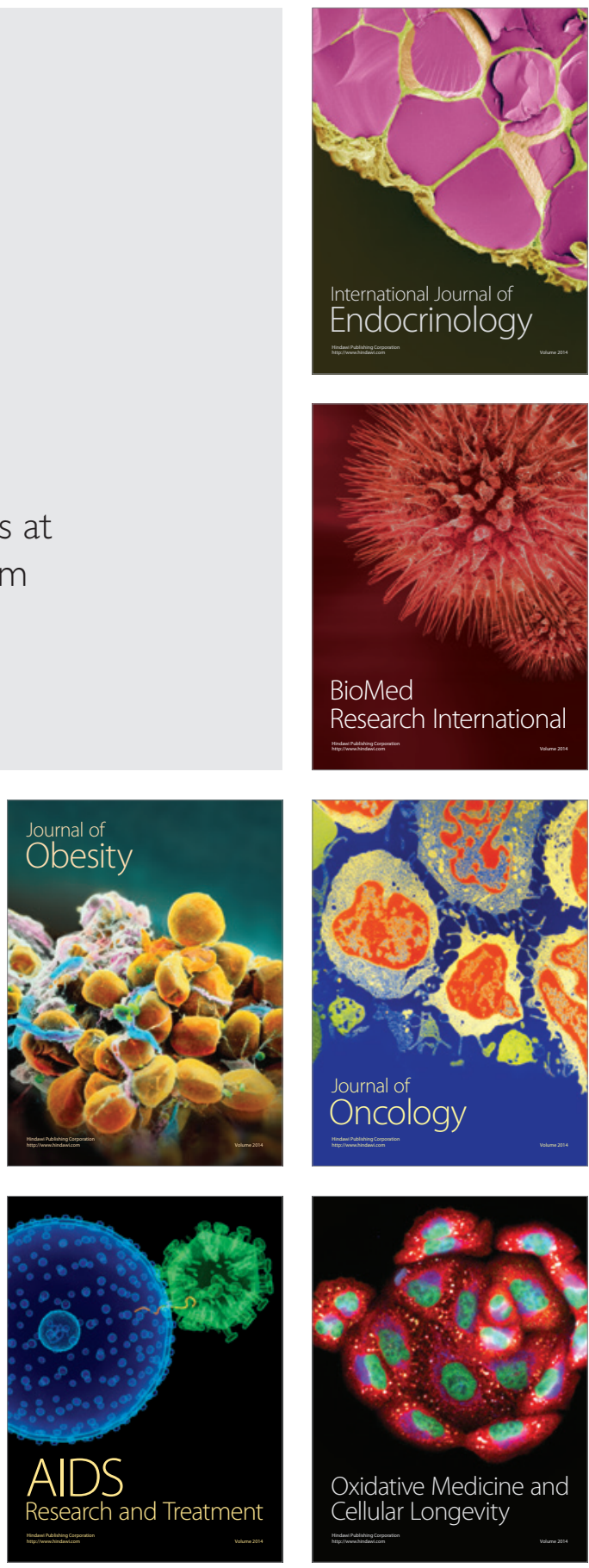